\title{
"Mãe Quilina": um Vídeo de uma Escola do Campo e seu Alcance nas Redes Sociais
}

\author{
Cláudio Rogério do Nascimento Pinto \\ Secretaria da Educação do Estado da Bahia (SEC) - Colégio Estadual João Carlos \\ Meireles Paulilo. Distrito Riacho da Guia, CEP 48.105-000 - Alagoinhas-BA - Brasil \\ claudio.web2@hotmail.com
}

\begin{abstract}
This article aims to analyze the reach in social networks of a video produced by students of the 3rd year of high school of the Leôncio Pereira dos Santos State College, located in the Estevão village, in the Alagoinhas-BA city. The intention is to report the references made to the video "Mãe Quilina" on Youtube and Facebook after the sharing of that audiovisual in these social networks. Therefore, it was verified the quantitative of visualizations, likes, comments and shares that occurred in each of the virtual environments. In the qualitative analysis, the netizens established a relation of the video with the customs of the past or the personal and family stories directly related to the midwife becoming a means for one of the dimensions of local history.
\end{abstract}

Resumo. Este artigo tem por objetivo analisar o alcance nas redes sociais de um vídeo produzido por estudantes do $3^{\circ}$ ano do Ensino Médio do Colégio Estadual Leôncio Pereira dos Santos, localizado no povoado Estêvão, em Alagoinhas-BA. Pretende-se relatar as menções feitas ao vídeo "Mãe Quilina" no You Tube e no Facebook após o compartilhamento daquele audiovisual nestas redes sociais. Para tanto, foram verificados o quantitativo de visualizações, curtidas, comentários e compartilhamentos ocorridos em cada um dos ambientes virtuais. Na análise qualitativa, os internautas estabeleceram uma relação do vídeo com os costumes do passado ou das histórias pessoais e familiares diretamente ligadas à parteira, tornando-se um meio para conhecer uma das dimensões da história local.

\section{Introdução}

Para o educador Miguel Arroyo (2007), a educação do campo no Brasil não vem conseguindo atender as demandas específicas da formação dos camponeses, sendo uma adaptação do currículo e das metodologias aplicados nas escolas urbanas.

A educação do campo é realizada, muitas vezes, com um currículo urbano, por professores urbanos, para estudantes urbanos, desconsiderando-se as demandas das famílias de agricultores familiares e as especificidades culturais, econômicas e políticas da zona rural. Os conteúdos propostos nas escolas de educação do campo, mesmo naquelas fisicamente instaladas em áreas rurais, em geral estão relacionados às problemáticas e às aspirações dos estudantes das cidades. Nesse contexto, a educação do campo tem tido como um dos seus desafios ensinar a crianças, jovens e adultos com 
base em um currículo específico e através de métodos que valorizem a cultura camponesa.

Este estudo foi desenvolvido com vistas a investigar: como a produção de mídia audiovisual pode contribuir para o desenvolvimento do processo de ensino aprendizagem no contexto da educação no campo, de forma mais articulada com as histórias e memórias coletivas da comunidade local do povoado de Estêvão, município de Alagoinhas/BA? O objetivo central reside em analisar o alcance nas redes sociais de um vídeo produzido por estudantes do $3^{\circ}$ ano do Ensino Médio do Colégio Estadual Leôncio Pereira dos Santos - CELPS, localizado no povoado Estêvão, na zona rural do município Alagoinhas-BA e compreender as possíveis contribuições da mídia audiovisual para o processo de ensino aprendizagem no contexto da educação no campo, partindo da experiência de produção realizada naquela escola.

O trabalho foi desenvolvido a partir de estudo bibliográfico, tomando principais referenciais, autores como: Lynn Alves(2005), Pierre Lévy (2000), José António Moreira \& Susana Januário (2014), Léa Leal \& Priscila Ferreira (2015), Miguel Arroyo (2007), Mary Valda Sales, Antonete Xavier \& Valnice Paiva (2017), Silva \& Pereira (2012) e da análise de experiência da produção de vídeo realizada por estudantes do $3^{\circ}$ ano do Ensino Médio do CELPS. Foi possível notar que um audiovisual compartilhado em rede tem sua exibição potencializada pela possibilidade de compartilhamento, indo a lugares e pessoas desconhecidas de quem o publica; além disso, no caso do vídeo "Mãe Quilina", usuários do Facebook demonstraram através dos comentários, curtidas e compartilhamentos terem sido tocados afetivamente.

\section{O Audiovisual, You Tube, Facebook e Educação: Relações Possíveis}

Considerando os aspectos técnicos, como a oferta no mercado de aparelhos para produção de conteúdos - gravadores e câmeras digitais, smartphones - assim como a criação de canais de comunicação e interação em plataformas multimídia, pode-se afirmar que estamos a atravessar um processo de transformações onde os indivíduos convivem em rede, construindo seus próprios conteúdos e reconfigurando conteúdos de outrem.

Nesta perspectiva, as redes sociais adensam-se e passam a ser ambientes fecundos para a troca de mensagens, a criação e compartilhamentos de conteúdos e a interação entre pessoas, vinculadas por conhecimento externo às redes sociais ou através dos "nós" hipermidiáticos do ciberespaço. Dentre essas redes sociais, ganhou espaço, em escala mundial, o You Tube, uma plataforma utilizada por usuários de diferentes idades, classes sociais, escolaridade, nacionalidades e focos de interesse, para publicar vídeos com conteúdos profissionais, familiares, pessoais, dentre outros. O Facebook é uma rede social criada por Mark Zuckeberg em 2004 "como rede privada universitária" (MOREIRA \& JANUÁRIO, 2014, p.75), tendo ganhado adeptos em diversas partes do mundo após passar a ser gerenciada comercialmente.

O uso das redes sociais tornou-se um imperativo da dinâmica contemporânea e a educação não pode prescindir de utilizar os meios de comunicação digitais para produzir e compartilhar conteúdos, sob pena de tornar-se obsoleta, distante da linguagem e das novas formas de relacionamento construídas da era digital. Os audiovisuais, devido às particularidades da sua linguagem, levam às pessoas mensagens nas quais se combinam 
imagens e sons que podem transmitir, simultaneamente, infindáveis informações ao espectador.

A linguagem audiovisual abre diferentes possibilidades e oportunidades educacionais. O mais importante, seguramente, não é descobrir as especificidades das técnicas, mas sim conhecê-las para utilizá-las pedagogicamente, fazendo delas instrumentos de criação, expressão e comunicação. Portanto a rápida evolução da tecnologia vem exigindo que todos ao longo da vida vivam em constante aprendizagem individual e coletiva, pois além de um direito tornou-se uma necessidade. (SALES et.al. 2017, p.12)

O conhecimento técnico de produção de vídeos, associado ao correto entendimento do uso pedagógico dos recursos audiovisuais e das redes sociais, pode potencializar a proposição de projetos que envolvam a pesquisa e a produção audiovisual com conteúdos voltados às questões do campo. O compartilhamento em rede abre a possibilidade de se alcançar o público externo, dando visibilidade às produções feitas pelos estudantes.

\section{Metodologia da Pesquisa}

Este trabalho foi desenvolvido inicialmente a partir de estudo bibliográfico, por meio do qual buscamos refletir sobre o possível uso e articulação da mídia audiovisual na educação. No segundo momento, tomamos como base para análise a experiência de produção de mídia audiovisual realizada com estudantes do ensino médio em uma escola do povoado de Estêvão, município de Alagoinhas-BA, a qual serviu como referência para compreensão sobre potencialidades do vídeo para contexto da educação no campo e como meio disseminador das histórias e memórias coletivas presentes na comunidade local.

\section{4. "Mãe Quilina"}

Mãe Quilina foi uma agricultora e parteira com grande influência no Estêvão nos anos 1960, 1970, 1980, 1990 e 2000, onde realizou centenas de partos de mulheres que viviam nas proximidades da sua residência e em localidades mais afastadas. Nascida em 1928 e falecida em 11 de agosto de 2006, atuou como parteira em um tempo em que os serviços de saúde e transporte eram mais escassos, especialmente em comunidades rurais, era comum as famílias optarem ou serem obrigadas a ter seus bebês em casa, ao invés de recorrerem a hospitais e à maternidade de Alagoinhas.

Mesmo com o desgaste físico comum da velhice e estando com a saúde fragilizada pelo diabetes, ainda encontrou forças para realizar o último parto, mesmo próximo da sua morte, ainda que houvesse a recomendação médica contrária à atividade de parteira e o monitoramento da família para que Dona Aquilina não realizasse esforços físicos, a parteira saiu escondido da família para trazer ao mundo mais uma criança. No dia do seu velório, muito moradores do Estêvão e povoados do entorno prestaram solidariedade à família e fizeram daquele momento uma oportunidade de homenagear Mãe Quilina, tanto as mulheres a quem ela serviu como parteira quanto os filhos dessas mulheres, todos gratos por terem sido paridos nas mãos de Dona Aquilina.

\section{O vídeo "Mãe Quilina"}

O vídeo tem a duração de cinco minutos e cinquenta e cinco segundos e, através de depoimentos de familiares e de amigos da família, é descrito o perfil emocional e afetivo e também como se desenvolviam as atividades de parteira da $\mathrm{Sr}^{\mathrm{a}}$ Aquilina Maria 
de Jesus. Na produção, foram utilizadas uma câmera semiprofissional da escola e câmeras de celulares dos estudantes, através das quais foram registrados depoimentos em momentos e lugares diferentes, principalmente na propriedade dos familiares de Mãe Quilina e dentro do Colégio Leôncio Pereira dos Santos. A edição foi concretizada no programa de edição de vídeo Windows Movie Maker, com o qual foi possível selecionar as falas mais significativas, adicionar uma fotografia de Dona Aquilina junto com alguns familiares e colocar as legendas, o fundo musical e os créditos do projeto.

Em um primeiro momento, foi solicitada aos estudantes a realização de uma pesquisa de campo em suas respectivas comunidades, para que pudessem, dialogando com as pessoas de mais idade das suas famílias ou da vizinhança, descobrir personagens da história local que tivessem, com suas práticas cotidianas, marcado a vida dos moradores. Em seguida, foi realizada pelo professor uma oficina de imagem e som, através da qual os estudantes puderam ter acesso às noções de iluminação e enquadramento, bem como às técnicas de entrevista a serem utilizadas para colher os depoimentos dos entrevistados. Após a escolha da história a ser filmada, os alunos produziram um questionário, agendaram a visita à família da Sra. Aquilina e gravaram os depoimentos mostrados no vídeo.

Foi realizada pelo professor a edição e a publicação do vídeo; primeiramente exibindo-o em uma sala na própria escola. Em 20 de maio de 2015, o vídeo foi postado no canal do professor no YouTube e, em 04 de setembro de 2016, compartilhado na conta do professor na rede social Facebook.

\section{O Alcance do Vídeo}

Primeiramente, deve-se considerar que, no ano de 2014, o Colégio Leôncio Pereira dos Santos teve 239 (duzentos e trinta e nove) estudantes matriculados nos três turnos: ensinos Fundamental II e Médio no matutino e no vespertino e Educação de Jovens e Adultos (EJA) no noturno

A análise do alcance do vídeo "Mãe Quilina", nas redes sociais You Tube e Facebook, apresentou os seguintes resultados:

Tabela 1. Dados coletados em: 01 de novembro de 2018

\begin{tabular}{|l|c|}
\hline \multicolumn{1}{|c|}{ YOU TUBE } & Publicado em: 20 de maio de 2015 \\
\hline Visualizações & 138 \\
\hline Curtidas & 8 \\
\hline Comentários & 1 \\
\hline
\end{tabular}

Os comentários listados a seguir foram adicionados no compartilhamento feito por um dos amigos do professor no Facebook:

Tabela 2. Dados coletados em: 01 de novembro de 2018

\begin{tabular}{|l|c|}
\hline \multicolumn{1}{|c|}{ FACEBOOK } & Publicado em: 04 de setembro de 2016 \\
\hline Visualizações & 628 \\
\hline Curtidas & 48 (4 “curti”; 3 “corações" e 1 "aplauso") \\
\hline Comentários & 10 \\
\hline Compartilhamentos & 15 \\
\hline
\end{tabular}


Ressalta-se o fato de 4 (quatro) dos 10 (dez) comentários no Facebook e o comentário no You Tube serem de internautas que não eram "amigos" online nem offline. Das 44 (quarenta e quatro) pessoas que adicionaram curtidas no Facebook, 16 (dezesseis) não eram "amigos" online nem offline. O único comentário no You Tube foi do usuário "loucoporfutebol", que adicionou a palavra "Lindo" para expressar seu contentamento com o vídeo.

\section{Possíveis Contribuições do Vídeo para o Processo de Ensino Aprendizagem no Contexto da Educação do Campo}

A produção de uma mídia audiovisual é um rico processo de construção coletiva do saber, pois agrupa, para agirem em equipe, sujeitos com diferentes ideias, interesses e formas de interpretar o mundo. Do ato mais simplório até as decisões mais complexas, a construção do vídeo desencadeou uma série de ações de colaboração que ensejaram o protagonismo dos estudantes em todo o processo de criação, transformando-os em pesquisadores, construtores efetivos do conhecimento através das pesquisas de campo e suas consequentes descobertas, podendo, futuramente, produzir seus próprios vídeos e revelarem novas histórias.

Por outro lado, o professor assumiu o papel de mediador da aprendizagem e condutor do processo de pesquisa, visando proporcionar a confecção de um produto final consistente e contextualizado, em sintonia com as necessidades específicas em que a escola está inserida. Um traço particular dos saberes da comunidade foi registrado e levado a público, valorizando uma história guardada apenas na memória de membros do povoado e, por meio das redes sociais You Tube e Facebook, alcançou pessoas em um espectro geográfico mais amplo do que os limites territoriais do Estêvão.

\section{Considerações Finais}

A mídia publicada recontou um pouco da história do povoado Estêvão e de uma figura pública importante para a comunidade, o que proporcionou aos alunos envolvidos no projeto experimentarem atividades de pesquisa científica na área das Ciências Humanas, conhecerem as noções básicas de fotografia e de vídeo, assumindo o protagonismo na produção do conhecimento.

Através de uma mídia digital audiovisual, emergiu de dentro da comunidade do Estêvão uma história quase desconhecida pelas gerações mais recentes. Com pouquíssimos recursos financeiros, e mesmo o compartilhamento não tendo sido realizado com intencionalidade pedagógica, foi possível dar visibilidade social à história da parteira Mãe Quilina e sensibilizar os internautas.

Resgatar, registrar e compartilhar as memórias coletivas presentes nas comunidades rurais se torna primordial para a que a história de povoados, lideranças políticas, religiosas e sociais do meio rural possa ser conhecida, transmitida e preservada.

\section{Referências}


Alves, Lynn R. G. (2005) "Game over: jogos eletrônicos e violência”. São Paulo: Futura.

Arroyo, Miguel Gonzalez (2007). "Políticas de formação de educadores(as) do campo". Cad. Cedes, Campinas, vol. 27, n. 72, p. 157-176, maio/ago. 2007. Disponível em http://www.cedes.unicamp.br. Acesso em: 15 de outubro de 2017

Leal, L. e Ferreira, Priscila d'Almeida (2015). Mídias na Educação: uma análise da construção da nova estrutura. In: Santos, Maria Silva et.al.(Orgs.) "Mídias na educação: construindo e inovando". Vitória da Conquista: Edições UESB.

Lévy, Pierre (2000). "Cibercultura”. São Paulo: Editora 34.

Marcelino, C. e Santos, R. dos (2015). Vídeos digitais na pesquisa em educação e cibercultura: narrativas e imagens com a rede social You Tube em convergência com ambientes virtuais de aprendizagem. In: Porto, Cristina. et.. al.(Orgs.) "Pesquisa e mobilidade na cibercultura: itinerâncias docentes". Salvador: Edufba.

Mattar, João (2010). "Games em educação: como os nativos digitais aprendem”. São Paulo: Pearson Prentice Hall.

Moreira, J. A. e Januário, S. (2014) Redes sociais e educação reflexões acerca do Facebook enquanto espaço de aprendizagem. In: Porto, C. e Santos, E. (Orgs.) . "Facebook e educação: publicar, curtir, compartilhar [online]". Campina Grande: EDUEPB. Disponível em: http://books.scielo.org. Acesso em: 18 out. 2018.

Porto, C. e Santos, E.(Orgs.) (2014). "Facebook e educação: publicar, curtir, compartilhar [online]". Campina Grande: EDUEPB. Disponível em: http://books.scielo.org. Acesso em: 18 out. 2018

Sales, M. V. S., Xavier, A. A. S. e Paiva, V. (2017). "Hiperbook- Ebook hipertextual". Salvador: UFBA.

Silva, B. D. e Pereira, M. da G. (2012). Reflexões sobre dinâmica e conteúdos da cibercultura numa comunidade educacional. In: Silva, Marco (Org.). "Formação de professores para docência online." São Paulo: Edições Loyola.

\section{Apêndices}

Link do vídeo no You Tube (data de postagem; visualizações, curtidas e comentários): https://www.You Tube.com/watch?v=n2pwbKChrT0\&t=287s 